\title{
Minimally invasive aortic valve replacement via right anterior minithoracotomy: Early outcomes and midterm follow-up
}

\author{
Mattia Glauber, MD, Antonio Miceli, MD, Stefano Bevilacqua, MD, and Pier A. Farneti, MD, Massa, Italy
}

Minimally invasive aortic valve replacement (MIAVR) is increasingly performed and has become an alternative to standard sternotomy. Compared with conventional surgery, MIAVR reduces postoperative mortality and morbidity as well as pain and provides better cosmetic results. ${ }^{1,2}$ Data reported from most of these studies focus on ministernotomy; outcomes after MIAVR via right anterior

From the Department of Cardiothoracic Surgery, Fondazione G. Monasterio, CNR-Regione Toscana, Massa, Italy.

Disclosures: Authors have nothing to disclose with regard to commercial support. Received for publication Jan 28, 2011; revisions received April 26, 2011; accepted for publication May 17, 2011; available ahead of print July 4, 2011.

Address for reprints: Antonio Miceli, MD, Fondazione G. Monasterio, CNR-regione

Toscana, 54100 Massa, Italy (E-mail: antoniomiceli79@alice.it).

J Thorac Cardiovasc Surg 2011;142:1577-9

$0022-5223 / \$ 36.00$

Copyright (C) 2011 by The American Association for Thoracic Surgery

doi:10.1016/j.jtcvs.2011.05.011 thoracotomy (RT) have not been well described. We report our experience with MIAVR via RT.

\section{PATIENTS AND METHODS}

From January 2005 to June 2010, 192 consecutive patients underwent isolated MIAVR via RT and were evaluated prospectively. Exclusion criteria for the RT approach were prior cardiac surgery, history of right-sided pleuritis, and aortic root dilatation. Outcome analysis was approved by the local ethical committee and individual consent was waived. All patients were seen 8 to 12 weeks postoperatively and thereafter were contacted for follow-up.

\section{Preoperative Planning and Surgical Technique}

Before surgery, all patients underwent imaging with a 64-slice computed tomographic scanner (Toshiba Aquilion; Toshiba Medical Systems, Tokyo, Japan) without contrast enhancement to evaluate aortic calcifications as well as the relationship among the aortic valve, the sternum, and intercostal spaces. Image interpretation was performed from reconstruction of axial and sagittal source images. Patients were suitable for RT if, at the level of main pulmonary artery, (1) more than half of ascending aorta was

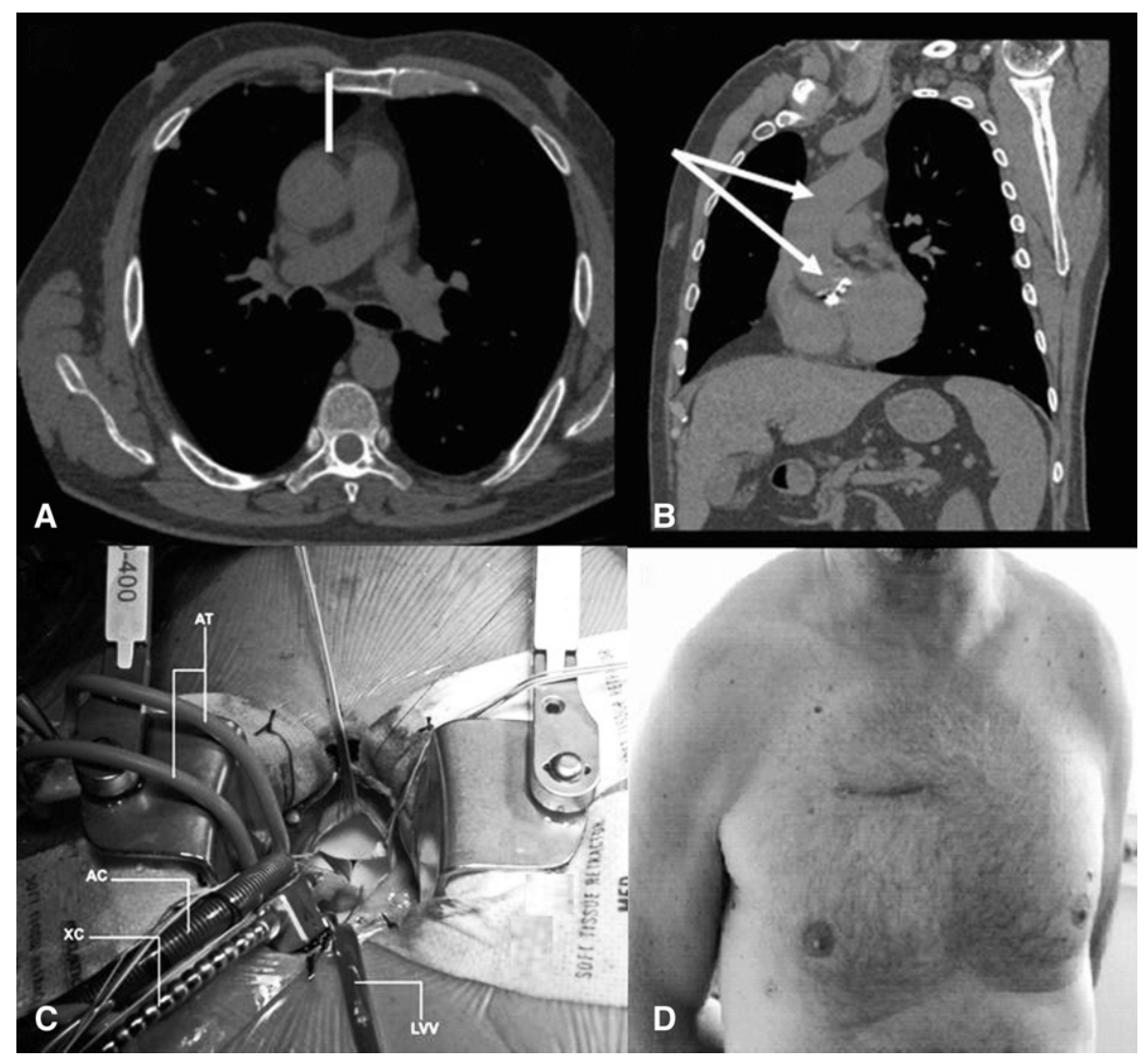

FIGURE 1. A, Axial plane shows the right position of the aorta with respect to the right border of the sternum. B, In the sagittal plane, arrows show the feasibility of cannulating the ascending aorta and replacing the aortic valve through the second intercostal space. C, Surgical field after aortic valve replacement. $A C$, Aortic cannula; $A T$, aortic tourniquet; $X C$, crossclamp; $L V V$, left ventricular vent. D, Final aesthetic result. 
TABLE 1. Preoperative and intraoperative characteristics

\begin{tabular}{lc} 
Age $(\mathrm{y} \pm \mathrm{SD}$ ) & $67.3 \pm 12.4$ \\
Female gender (no. patients, \%) & $59(31)$ \\
COPD (no. patients, \%) & $25(13.4)$ \\
Hypertension (no. patients, \%) & $130(68)$ \\
Diabetes mellitus (no. patients, \%) & $37(19)$ \\
NYHA III-IV functional class (no. patients, \%) & $49(26)$ \\
Ejection fraction (\%) & $56 \pm 7$ \\
Aortic valve disease (no. patients, \%) & \\
$\quad$ Aortic stenosis & $90(47)$ \\
$\quad$ Aortic regurgitation & $40(21)$ \\
$\quad$ Combined lesions & $62(32)$ \\
EuroSCORE (median, range) & $5.2(2.5-8.6)$ \\
Aortic femoral-venous cannulation (no. patients, \%) & $173(90)$ \\
Arterial femoral-venous femoral cannulation & $19(10)$ \\
$\quad$ (no. patients, \%) & \\
Prosthetic valve type (no. patients, \%) & \\
$\quad$ Biologic & $160(83)$ \\
$\quad$ Mechanical & $32(17)$ \\
CPB time (min \pm SD) & $123 \pm 45$ \\
Crossclamp time (min \pm SD) & $89 \pm 32$ \\
\hline
\end{tabular}

$S D$, Standard deviation; $C O P D$, chronic obstructive pulmonary disease; $N Y H A$, New York Heart Association; $C P B$, cardiopulmonary bypass.

located on the right in respect to a vertical line drawn from the right sternal border to the ascending aorta and (2) the distance from the ascending aorta to sternum did not exceed $10 \mathrm{~cm}$ (Figure 1, A).

The patients were positioned supine and intubated with a single-lumen endotracheal tube after induction of general anesthesia (single lung ventilation was not required for preparation of the operative field). Defibrillator pads were placed on the chest wall.

MIAVR was performed via RT through a skin incision of 5 to $7 \mathrm{~cm}$ placed on the second or third intercostal space without rib resection (Figure 1, $B$ and $C$ ). The right internal thoracic artery was excluded from the surgical field with a soft tissue retractor (CardioVation; Edwards Lifesciences, Inc, Irvine, Calif, or Estech, San Ramon, Calif). Direct ascending aortic cannulation was performed using flexible cannulas such as Easyflow (Estech) or Straightshot cannulas (Edwards Lifesciences). Percutaneous femoral venous cannulation was used with a variety of cannulas: BioMedicus multistages (Medtronic, Inc, Minneapolis, Minn), Quickdraw (Edwards Lifesciences), RAP (Estech), or Smartcanula (Smartcannula LLC, Lausanne, Switzerland). The cannulas were placed over a wire with echocardiographic guidance. After establishment of cardiopulmonary bypass with vacuum-assisted drainage $(-40$ to $-60 \mathrm{~mm} \mathrm{Hg})$, a vent was inserted through the right superior pulmonary vein. The patients were cooled to $34^{\circ} \mathrm{C}$, the aorta was crossclamped with a Cygnet crossclamp (Novare Surgical Systems, Cupertino, Calif) or a specifically designed clamp (Cardiomedical $\mathrm{GmbH}$, Langenhagen, Germany), ${ }^{3}$ and antegrade cardioplegic solution was given into the aortic root or selectively into the coronary ostia. The final result is shown in Figure 1, $D$.

\section{RESULTS}

Patients' characteristics are presented in Tables 1 and 2. In-hospital mortality was $1.6 \%$. One patient with Horton arteritis died of late aortic dissection, and 2 patients died of pneumonia. Three $(1.6 \%)$ patients had intraoperative conversion to sternotomy for either paravalvular leaks $(\mathrm{n}=1)$ or severe pleural adhesions $(\mathrm{n}=2)$. No wound
TABLE 2. Early postoperative outcomes

\begin{tabular}{lc}
\hline Overall mortality (no. patients, \%) & $3(1.6)$ \\
Convertion to sternotomy (no. patients, \%) & $3(1.6)$ \\
Reexploration for bleeding (no. patients, \%) & $12(6)$ \\
Postoperative renal dysfunction (no. patients, \%) & $4(2)$ \\
Stroke (no. patients, \%) & $1(0.5)$ \\
Atrial fibrillation (no. patients, \%) & $35(18)$ \\
Blood transfusion (no. patients, \%) & $31(16)$ \\
Ventilation time, h (median, range) & $6(5-9)$ \\
Length of stay, d (median, range) & $5(4-6)$ \\
\hline
\end{tabular}

infections were reported. Other postoperative outcomes are reported in Table 2. Discharge home was $90 \%$. At a median follow-up of 24 months (interquartile range, 12-41 months), 1 noncardiac death occurred and freedom from reoperation was $99 \%$. One patient required a new aortic valve replacement for acute bioprosthesis failure. Ninety-five percent of the patients were in New York Heart Association functional class I, 96\% believed they had an aesthetically pleasing scar, and $93 \%$ were back to their normal activities within 4 weeks.

\section{DISCUSSION}

The rationale of MIAVR is to reduce postoperative morbidities, shorten hospital stays with faster recovery, improve cosmetic results, and reduce costs. ${ }^{1,2,4}$ Few studies have reported outcomes after MIAVR via RT. Our study shows that RT is a safe procedure associated with low mortality and postoperative complications. The in-hospital mortality of $1.5 \%$ is lower than the recent mortality rate reported in the Society of Thoracic Surgeons Database. ${ }^{5}$ Although crossclamping and cardiopulmonary bypass time were longer than in the standard approach, the low incidence of postoperative stroke, renal failure, atrial fibrillation, and blood transfusions, as well as the short postoperative recovery, are concordant with other minimally invasive approaches, highlighting the safety of this procedure. ${ }^{1,2,4}$ Reexploration for bleeding was more common than expected, however; its incidence ranges from $3 \%$ to $8 \%$ according to others. ${ }^{2}$ Finally, patients expressed high satisfaction in terms of early return to work, symptoms, and cosmetic results with no wound infections. In conclusion, MIAVR via RT can be performed with excellent early and midterm results and high patient satisfaction. Sutureless technology will probably shorten cardiopulmonary bypass and crossclamp time, further facilitating this procedure.

\section{References}

1. Brown ML, McKellar SH, Sundt TM, Schaff HV. Ministernotomy versus conventional sternotomy for aortic valve replacement: a systematic review and meta-analysis. J Thorac Cardiovasc Surg. 2009;137:670-9.

2. Martuza B, Pepper JR, Stanbridge RD, Jones C, Rao C, Darzi A, et al. Minimal access aortic valve replacement: is it worth it? Ann Thorac Surg. 2008;85:1121-31. 
3. Modi P, Rodriguez E, Hargrove WC, Hassan A, Szeto WY, Chitwood WR. Minimally invasive video-assisted mitral valve surgery: a 12-year, 2-center experience in 1178 patients. J Thorac Cardiovasc Surg. 2009;137:1481-7.

4. Glauber M, Karimov JH. A completely detachable aortic clamping instrument for minimally invasive cardiac surgery. Innovations. 2010;5:309-10.
5. Brown JM, O'Brien SM, Wu C, Sikora JA, Griffith BP, Gammie JS. Isolated aortic valve replacement in North America comprising 108,687 patients in 10 years: changes in risks, valve types, and outcomes in the Society of Thoracic Surgeons National Database. J Thorac Cardiovasc Surg. 2009;137: 82-90.

\title{
Split, in situ left internal thoracic artery to revascularize left anterior descending coronary artery system
}

\author{
Dusko Nezic, MD, PhD, FETCS, Zelimir Antonic, MD, Aleksandar Knezevic, MD, BcS, and \\ Zeljko Bojovic, MD, Belgrade, Serbia
}

The in situ pedicled left internal thoracic artery (LITA) conduit is generally accepted as the coronary artery bypass conduit of choice because of matchless results for its grafting on the left anterior descending (LAD) coronary artery. ${ }^{1}$ Therefore, for carefully selected patients, we have adopted a simple and practical technique of splitting the LITA conduit $^{2}$ and using its proximal and distal parts as in situ arterial grafts to revascularize the LAD coronary artery bed.

\section{CLINICAL SUMMARY}

A 66-year-old man was admitted with progressive postinfarction angina. Hypertension, smoking, hypercholesterolemia, and insulin-dependent type 2 diabetes mellitus were his risk factors for coronary artery disease. Transthoracic echocardiography showed moderately impaired left ventricular function (ejection fraction of 0.35 , with regional inferoposterior and apicolateral akinesia). Angiocardiography revealed triple-vessel disease ( $99 \%$ stenoses of the right coronary artery and its posterior descending branch, a 95\% stenosis of the huge diagonal branch, and an $80 \%$ stenosis of the circumflex coronary artery). The distal part of the occluded LAD was vaguely filled by collaterals from the right coronary artery (Figure 1).

Coronary artery bypass grafting using split, pedicled LITA and vein grafts was planned and accomplished. After full heparinization $(4 \mathrm{mg} / \mathrm{kg})$, the harvested in situ LITA conduit was divided at the junction of the upper two thirds and lower one third. The measured flows of the proximal

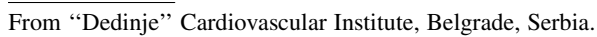

Disclosures: Authors have nothing to disclose with regard to commercial support.

Received for publication March 9, 2011; revisions received May 8, 2011; accepted for publication May 17, 2011; available ahead of print June 27, 2011.

Address for reprints: Dusko Nezic, MD, PhD, FETCS, Chief, Department of Cardiac

Surgery I, "Dedinje" Cardiovascular Institute, M. Tepica 1, 11000 Belgrade,

Serbia (E-mail: nezic@eunet.rs; nezic@ikvbd.com).

J Thorac Cardiovasc Surg 2011;142:1579-80

0022-5223/\$36.00

Copyright (c) 2011 by The American Association for Thoracic Surgery

doi:10.1016/j.jtcvs.2011.05.012 and the distal in situ LITA conduits were $130 \mathrm{~mL} / \mathrm{min}$ and $105 \mathrm{~mL} / \mathrm{min}$, respectively. The proximal LITA was used to revascularize the large diagonal branch, antegradely, in a conventional manner with an end-to-side anastomosis. The distal LITA (supplied by its superior epigastric and musculophrenic branches) revascularized the distal, occluded LAD in a retrograde fashion. Care was taken to anchor the distal LITA pedicle precisely with stay sutures to avoid tension on or kinking of the conduit or anastomosis. Vein grafts anastomoses to the right and circumflex

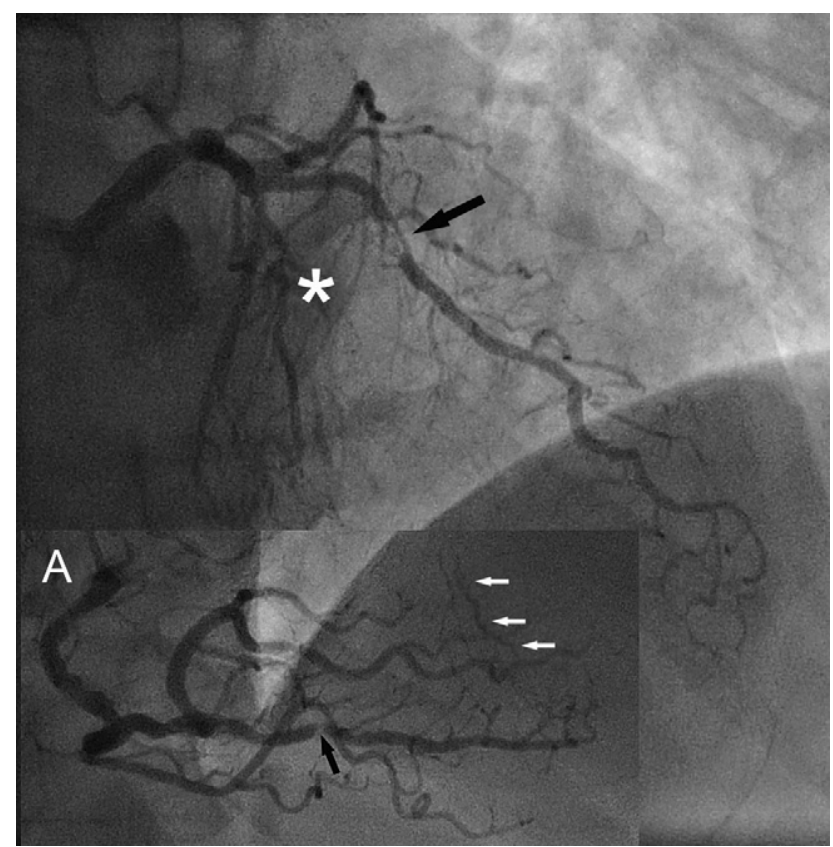

FIGURE 1. Preoperative angiography showed occluded left anterior descending (LAD) coronary artery (white asterisk) and 95\% stenosis of a huge diagonal branch (black arrow). Inset A, Preoperative angiography showed $99 \%$ stenoses of the right coronary artery and its posterior descending branch (black arrow) and the distal part of the occluded LAD that was vaguely filled by collaterals from the right coronary artery (white arrows). 